\title{
The use of internet platforms for oral health information and associated factors among adolescents from Jakarta: a cross sectional study
}

\author{
Diah Ayu Maharani ${ }^{*} \mathbb{B}$, Maha El Tantawi², Marsha Griselda Yoseph ${ }^{1}$ and Anton Rahardjo ${ }^{1}$
}

\begin{abstract}
Background: The growth of the internet has increased its use to obtain health information including oral health information (OHI). This study assessed Indonesian adolescents' use of different internet platforms to obtain $\mathrm{OHI}$ and factors associated with this use.

Methods: A cross-sectional study surveyed middle school students in five regions in Jakarta in 2019. Participants completed a questionnaire that assessed demographics, oral health practices (toothbrushing and dental visits), the presence of dental pain, using internet platform to obtain $\mathrm{OH}$ and type of information searched for. Multinomial logistic regression was used to assess the association between using the internet for OHI (Google, Social Media (SM), both or none) and the independent factors: demographics, oral health practice, dental pain and whether participants search for causes, symptoms, prevention or treatment of oral diseases (ODs).

Results: Most of the 521 participants were female (55.7\%) with mean age $=13.4$ years. Almost all of them (93.7\%) searched the internet for OHI through Google (40.7\%) or Google with SM (36.1\%). Searching for OHI over SM was significantly associated with toothbrushing $(\mathrm{OR}=4.12,95 \% \mathrm{Cl}=1.43,11.89)$ and less dental visits $(\mathrm{OR}=0.16,95 \%$ $\mathrm{Cl}=0.05,0.60$ ). Searching Google for $\mathrm{OHI}$ was significantly associated with looking for information about causes $(\mathrm{OR}=3.69,95 \% \mathrm{Cl}=1.33,10.26)$ and treatment $(\mathrm{OR}=6.17,95 \% \mathrm{Cl}=2.23,17.03)$ of $\mathrm{ODs}$.
\end{abstract}

Conclusions: Most adolescents used Google to seek $\mathrm{OHI}$. Oral health practices and types of $\mathrm{OHI}$ searched for differed by internet platform. Dental health professionals should consider using internet-based interventions to promote oral health to this age group.

Keywords: Adolescents, Oral health information, Social media, Indonesia

\section{Background}

Adolescents usually have high prevalence of dental caries, trauma, and periodontal disease [1]. A previous study reported a high prevalence of oral diseases among

\footnotetext{
*Correspondence: diah.ayu64@ui.ac.id

1 Department of Preventive and Public Health Dentistry, Faculty of Dentistry, Universitas Indonesia, Jalan Salemba No. 4, Jakarta 10430, Indonesia

Full list of author information is available at the end of the article
}

Indonesian adolescents where $61 \%$ of 12 -year-old adolescents in Jakarta, Indonesia had dental caries [2]. Neglecting oral hygiene in adolescents negatively affects dental caries, periodontal diseases in addition to social and emotional well-being [3]. Oral hygiene may also have implications on social acceptability and self-esteem [4].

When children are young, decisions are predominantly made by parents or caregivers because children's decision-making abilities are not adequately formed. During adolescence, cognitive functioning improves with age 
and teenagers can start making and applying decisions to obtain the best possible outcome [5]. Four capacities are required for adolescents to make their own healthcare decisions: expressing a choice, understanding, reasoning, and appreciation [6]. At this developmental stage, behavior modification is important to foster proper self-care habits that can help reduce oral diseases and hopefully last throughout life [7].

Using social media (SM) is one of the most common activities of today's adolescents. Websites that allow social interaction are considered SM platforms, allowing users to communicate, develop their creativity, expand their knowledge and obtain health information. Searching for health information online may make users feel more secure in expressing their primary concerns because their identities are masked and their privacy is guaranteed [8] and users can engage with content generated by others [9]. Health information can be disseminated through a variety of forms over SM such as blogs, podcasts, tweets, Facebook pages or posts, and YouTube videos [10]. A previous study showed that adolescents also used SM to seek oral health information (OHI) [11]. This may be especially relevant in Indonesia where it was reported that users spend more time on the internet than users in other parts of the world [12]. Thus, the internet may offer an opportunity to disseminate OHI targeting Indonesians adolescents.

Understanding how $\mathrm{OHI}$ is obtained over the internet helps in developing internet-based health education programs and allows the selection of the proper internet platform to disseminate $\mathrm{OHI}$ for adolescents so that health education messages are tailored to the needs and interests of the target group with potentially better engagement. It is important to understand whether adolescents use SM to search for OHI thus depending on word of mouth and experiences of peers or search Google which may direct them to websites of professional organizations, dentists or companies selling oral health care products. The objectives of this study were to assess the use of different internet platforms to obtain OHI by adolescents in Jakarta, and the factors associated with this use. The null hypothesis of the study was that adolescents would equally use search engines such as Google and SM to obtain OHI.

\section{Methods}

\section{Study design and participants}

A cross-sectional, questionnaire-based study was conducted among middle school students in five areas of Jakarta (North, South, East, West, Central) in October 2019. Jakarta is the capital and largest city of Indonesia which is the 4th most populous country in the world [2]. Sample size was calculated based on assuming a margin of error $=5 \%$, confidence level $=95 \%$, and percentage of adolescents using SM to obtain $\mathrm{OHI}=58 \%$ [11]. The required sample size was 374 participants, increased by $30 \%$ to compensate for potential nonresponse. Adolescents were included if they went to middle school (private or public) in Jakarta, had no physical or intellectual disability preventing them from responding to the questionnaire and if their parent/guardian consented to their participation and they assented. The government provided a list of middle schools in the city. In each of the five administrative districts of Jakarta, schools were randomly selected so that it would be possible to recruit a number of students proportional to the size of the population living in that district. Participants were selected using cluster sampling from each school. This method resulted in the random selection of a total of 14 schools with 50 students from Central Jakarta, 70 students from North Jakarta, 148 students from West Jakarta, 109 students from South Jakarta and 144 students from East Jakarta.

\section{Data collection tool}

A questionnaire was designed based on the one used by El Tantawi et al. [11]. The original questionnaire was translated to Bahasa Indonesia, the main language used in Indonesia then back translated to English and compared with the original English version to resolve inconsistencies. Some words were modified so that their meaning in the Bahasa Indonesian version would be similar to the original English version. Further, a pilot test of the modified questionnaire was conducted among adolescents to determine clarity and comprehensiveness of the wording. The final questionnaire was used as a self-administered Bahasa Indonesia form. The questionnaire was divided into three sections. The first section collected personal information including gender, date of birth, whether parents were university educated and whether the mother was a housewife. The second section assessed oral health practices including brushing twice daily and regular visits to the dentist and presence of dental pain in the last six months using close-ended questions with yes or no responses. The third section assessed the use of Internet for OHI. Participants were asked about the internet platforms they used to search for OHI: whether they used Google or a number of SM. They were also asked about the $\mathrm{OHI}$ they looked for covering aspects of oral diseases (ODs) including causes, symptoms, prevention and treatment. The students received the questionnaires on school premises and were given 5-10 min to respond to its items anonymously and the forms were collected afterwards. Data were entered into IBM SPSS for Windows version 23.0 (IBM Corp., Armonk, N.Y., USA) and cleaned for analysis. 


\section{Data analysis}

Descriptive analysis was conducted and summary measures were calculated as means and standard deviations or frequencies and percentages. A new variable "using SM" was created by counting users of any type of SM. The dependent variable was using various internet platforms to obtain OHI (categorized into using Google, SM, both, or none) and the independent variables included factors reflecting interest in oral health based on their adoption of oral health practices such as brushing and dental

Table 1 Personal profile, toothbrushing, dental visits and dental pain among students participating in the study

\begin{tabular}{lr}
\hline Variables & n (\%) \\
\hline Gender & \\
Male & $231(44.3)$ \\
Female & $290(55.7)$ \\
Father's education & \\
University educated & $181(34.7)$ \\
Non-university educated & $340(65.3)$ \\
Mother's education & \\
University educated & $170(32.6)$ \\
Non-university educated & $351(67.4)$ \\
Housewife mother & \\
Yes & $256(49.1)$ \\
No & $265(50.9)$ \\
Brushes twice daily & \\
Yes & $424(81.4)$ \\
No & $97(18.6)$ \\
Regular visit to the dentist & \\
Yes & $61(11.7)$ \\
No & $460(88.3)$ \\
Had dental pain in the last 6 months & \\
Yes & $115(22.1)$ \\
No & $406(77.9)$ \\
\hline
\end{tabular}

visits and the need for OHI due to the presence of dental pain. The independent factors also included searching for $\mathrm{OHI}$ about various aspects of ODs. Multinomial logistic regression analysis was used to assess the association between the dependent and independent variables adjusted for personal factors as confounders. Odds ratios and $95 \%$ confidence intervals (CIs) were calculated. Significance was set at $5 \%$.

\section{Results}

The parents of all students who were invited to join the study consented to their participation and the students assented $(n=521$, response rate $=100 \%)$. Table 1 showed that most participants were female $(n=290 ; 55.7 \%)$ with mean age $=13.4 \pm 1$ year old. The age of the respondents ranged from 11-17 years old. Most parents were nonuniversity educated (father $=65.3 \%$ and mother $=67.4 \%$ ), with half mothers being housewives (49.1\%). Most participants brushed twice daily $(81.4 \%)$, did not regularly visit the dentist (88.3\%) and had no dental pain in the last 6 months (77.9\%). The overall average time that they spend using the internet per day is $3.2 \pm 1.9 \mathrm{~h}$ per day.

The results show that $40.7 \%$ used Google to search for OHI, 16.9\% used SM and 36.1\% used both Google and SM with a total of $93.7 \%$ using some internet platform to search for OHI. Participants using SM used YouTube (40.7\%), Instagram (24\%), Facebook (5\%) and Twitter (1.7\%). About $49.3 \%$ reported searching for OHI about treatment, $47.6 \%$ about prevention, $43.4 \%$ about causes and $14.6 \%$ about symptoms of ODs.

Table 2 shows that various factors were differently associated with using Google, SM or both compared to not using the internet at all to obtain OHI. Brushing twice daily was associated with significantly greater likelihood of using $\mathrm{SM}(\mathrm{OR}=4.12,95 \% \mathrm{CI}=1.43,11.89)$ and both Google and SM $(\mathrm{OR}=2.70,95 \% \mathrm{CI}=1.03,7.08)$ but was not significantly associated with using Google

Table 2 Factors associated with using Google, SM, and Google and SM combined for OHI versus not using the internet for $\mathrm{OHI}$ by adolescents in Jakarta, Indonesia

\begin{tabular}{|c|c|c|c|}
\hline & \multicolumn{3}{|l|}{ OR $(95 \% \mathrm{Cl})$} \\
\hline & Google & SM & Google and SM combined \\
\hline Brushes twice daily & $2.10(0.84,5.24)$ & $4.12(1.43,11.89)^{*}$ & $2.70(1.03,7.08)^{*}$ \\
\hline Visiting the dentist regularly & $0.42(0.15,1.17)$ & $0.16(0.05,0.60)^{*}$ & $0.42(0.14,1.23)$ \\
\hline Had dental pain in the last 6 months & $0.92(0.36,2.33)$ & $1.36(0.50,3.69)$ & $1.12(0.43,2.96)$ \\
\hline Searching for ODs causes & $3.69(1.33,10.26)^{*}$ & $3.49(1.18,10.26)^{*}$ & $6.98(2.46,19.79)^{*}$ \\
\hline Searching for ODs symptoms & $2.26(0.46,11.06)$ & $1.58(0.28,8.88)$ & $6.07(1.24,29.87)^{*}$ \\
\hline Searching for ODs treatment & $6.17(2.23,17.03)^{*}$ & $5.13(1.75,15.01)^{*}$ & $9.86(3.46,28.06)^{*}$ \\
\hline Searching for ODs prevention & $2.22(0.93,5.32)$ & $1.66(0.65,4.25)$ & $4.82(1.95,11.89)^{*}$ \\
\hline
\end{tabular}

Adjusted for region, gender, age, parents' education and mother's job

* Statistically significant at $\mathrm{P}<0.05$ 
alone $(\mathrm{OR}=2.10,95 \% \mathrm{CI}=0.84,5.24)$. Regular dental visits were associated with significantly lower likelihood of using $\mathrm{SM}(\mathrm{OR}=0.16,95 \% \mathrm{CI}=0.05,0.60)$ but had no significant association with using Google alone $(\mathrm{OR}=0.42,95 \% \mathrm{CI}=0.15,1.17)$ or using both Google and $\mathrm{SM}(\mathrm{OR}=0.42,95 \% \mathrm{CI}=0.14,1.23)$. Exclusive users of Google and SM alone were significantly more likely than those who did not use the internet for OHI to be looking for information about $\mathrm{ODs}$ causes $(\mathrm{OR}=3.69$, $95 \% \mathrm{CI}=1.33,10.26$ and $3.49,95 \% \mathrm{CI}=1.18,10.26)$ and treatment $(\mathrm{OR}=6.17,95 \% \mathrm{CI}=2.23,17.03$ and $\mathrm{OR}=5.13,95 \% \mathrm{CI}=1.75,15.01$ ) while users of both Google and SM together were significantly more likely than non-users of the internet to be looking for $\mathrm{OHI}$ about symptoms $(\mathrm{OR}=6.07,95 \% \mathrm{CI}=1.24,29.87)$ and prevention $(\mathrm{OR}=4.82,95 \% \mathrm{CI}=1.95,11.89)$ in addition to causes $(\mathrm{OR}=6.98,95 \% \mathrm{CI}=2.46,19.79)$ and treatment $(\mathrm{OR}=9.86,95 \% \mathrm{CI}=3.46,28.06)$.

\section{Discussion}

The study showed that the internet was used by almost all the adolescents participating in the study to obtain $\mathrm{OHI}$ with the majority using Google alone or in combination with SM. The search mainly focused on treatment and causes of ODs. Using SM for OHI was less likely for those who visited the dentist regularly and those who did not brush their teeth. The findings highlight the importance of the internet as a source of $\mathrm{OHI}$ in this vulnerable age group and draw the attention of dental professionals to the need to monitor the accuracy of $\mathrm{OHI}$ which is posted in most cases without quality control [13]. The findings also suggest the possibility of using the internet to offer $\mathrm{OHI}$ to adolescents using websites of professional organizations and other agencies that can be retrieved through Google search. The evidence does not support the claim that the SM are the most frequent source of $\mathrm{OHI}$ for adolescents and thus, the null hypothesis of the study is rejected. The study showed the ubiquitous use of internet and SM by adolescents. This agrees with previous studies that highlighted the ease of use and accessibility of the internet and SM through mobile devices where they can be accessed and used any time $[11,14]$.

Google was the most popular internet platform for $\mathrm{OHI}$ in the present study. This agrees with another study where the role of Google as a search engine was reported to be particularly important because Google actively mediates and shapes the information seen by its users [14]. Previous research showed that search engines such as Google offered a variety of content and had minimal advertisements. Information provided through Google can be checked through its preview feature without the need to visit the original website, thus allowing users to skim through information directly [15]. The present findings agree with Fan et al. [16] who reported that adult users searched Google more than SM for information about plastic surgery. Google have shown how the pervasive internet, connectivity, big data analytics and artificial intelligence can be used to dissolve boundaries and constraints, build closer relationships with adolescents, learn more about their behaviors and preferences, and deliver highly personalized experiences and products in sustainable and cost-effective ways [17].

The present study showed that YouTube was the most popular SM for OHI. The videos offered on YouTube engage multiple senses, including hearing and seeing at the same time which is helpful for information retention. People may remember up to $10 \%$ of what they read, $20 \%$ of what they hear, $30 \%$ of what they see, and $50 \%$ of what they see and hear [18]. The study findings differ from those of El Tantawi et al. where Saudi adolescents preferred using Instagram for $\mathrm{OHI}$ [11] indicating that use of different types of SM for OHI may differ by country or culture or even by time as certain SM become popular. For example, a 2012 survey [19] showed that Jakarta was the most active Twitter city in the world although the use of Twitter in the present study was reported by a minor portion of users. The difference between that report and the present findings may be explained by the eight years that passed since this report during which the SM stage in the country has changed. By contrast, another recent report in 2019 [20] showed that YouTube was the most popular SM in Indonesia with penetration rate $>88 \%$ which agrees with the predominance of YouTube observed in the current study.

The study showed that using SM for OHI was directly associated with toothbrushing. This may suggest that searching for $\mathrm{OHI}$ over $\mathrm{SM}$ is more frequent among those who already adopt self-care practices such as tooth brushing to maintain oral health. The findings also showed that searching SM for OHI was inversely associated with regular dental visits. This may be attributed to the availability of OHI through the dentist during these visits which reduces the need for searching for answers to questions about ODs over SM.

In the present study, dental pain was directly associate with obtaining $\mathrm{OHI}$ from SM and inversely associated with obtaining $\mathrm{OHI}$ from Google. This agrees with Bounsanga et al. [21] who reported better health among adults with health information obtained from the internet but not with information obtained from SM. The associations observed in the present study were not statistically significant possibly indicating minimal impact of $\mathrm{OHI}$ on oral health status and dental pain which may be partly explained by the low prevalence of dental pain in the present study reducing the power to detect significant associations in addition to the young age of the participants 
which allowed limited duration for OHI to affect oral health status and pain. However, it is important to interpret these findings within the framework of the crosssectional nature of the study which makes it impossible to prove that participants were exposed to $\mathrm{OHI}$ before pain assessment and that OHI may, therefore, potentially reduce/change pain. Further longitudinal studies are needed to assess causality between exposure to $\mathrm{OHI}$ from various sources and oral status or dental pain. Confounder identification is important. Personal factors were considered as confounders in this study. Without proper adjustment for confounders, the association will be a biased estimate of the true association. The confounders were adjusted by controlling it with appropriate statistical techniques [22].

The present study draws attention to the importance of $\mathrm{OHI}$ on the internet because of the great interest of adolescents in it. Dental professionals may need to direct their attention toward these tools for the dissemination of OHI. Translating research findings into easy-tounderstand language and disseminating these findings to attract the attention of online users may help provide evidence-based OHI material [23]. There is a need to explore the quality of $\mathrm{OHI}$ currently available on Google and YouTube in Bahasa Indonesia. The present study is limited by its cross-sectional design which suggests association but cannot prove causality. The study included adolescents only from Jakarta which is one city in Indonesia. However, it is the largest city in the country and the profile of its population generally reflects the characteristics of the population including adolescents all over the country [2].

Adolescents possessing capacities required for decision-making, such as understanding the choices and reasoning of the decision being made, may need support of facilitating environmental factors [6]. This process might be explained by behavioral theories. The social learning theory assumes that behavior is learnt from the environment through observation [24]. This suggests that SM imagery content has the potential to influence oral health behavior. Furthermore, the theory of presumed media influence persuasive media messages influence attitudes indirectly by changing perceptions of descriptive norms among peers [25]. Another theory, the theory of planned behavior [26] treats attitudes and norms as separate factors influencing behavior and does not consider how beliefs and attitudes might influence injunctive norms. Therefore, it is essential to further conduct studies to develop appropriate $\mathrm{OHI}$ for adolescents, given the possibilities of different theories as a base of explaining the efficacy of the information delivered. SM has the potential to reach and influence a broad audience, particularly as a means of engagement rather than just disseminating information. Audio-visual SM may be more efficient for oral health promotion amongst adolescent when compared to solely text-based medium [27]. Clinicians interested in using YouTube and other SM for broad reach to adolescents may benefit from engaging adolescents in creating powerful and effective SM messages. It was reported that adolescents were more engaged with videos posted by their peers, which may have been viewed as easier to understand [28].

\section{Conclusion}

Based on the findings of this study, most adolescents in Jakarta used the internet to obtain OHI focusing more on Google than SM. There are differences among adolescents searching Google and SM for OHI based on oral health practices and the type of OHI addressing specific aspects of ODs.

\section{Abbreviations}

$\mathrm{OHI}$ : Oral health information; SM: Social media; ODs: Oral diseases.

\section{Acknowledgements}

Not applicable.

\section{Authors' contributions}

DAM and AR supervised the study and contributed to the conception of the study. MGY contributed to the acquisition of data. MET contributed to the statistical analysis and data interpretation. DAM and MET revised the manuscript critically for important intellectual content and contributed to the drafting and finalizing of the manuscript. AR and MGY dealt with local bureaucracy, obtained study permits, and acted as a liaison to obtain ethical clearance. All authors have approved the final version and agreed to be accountable for all aspects of the work.

\section{Funding}

This research was supported by grants from Universitas Indonesia. Financial support included for the data collection and presentation of results.

\section{Availability of data and materials}

The raw data are available from the authors to any author who wishes to collaborate with us.

\section{Ethics approval and consent to participate}

Ethical approval was granted by the Research Ethics Committee of the Faculty of Dentistry, Universitas Indonesia (approval no. 68/Ethical Approval/ FKGUI/VIII/2019). This research was conducted in full accordance with the World Medical Association Declaration of Helsinki. The principal investigator is responsible for ensuring the confidentiality of the study documents and protecting the anonymity of all respondents. Written informed consent was provided by the parents and participating adolescents assented to participating. Written informed consent was also obtained from participants who are 16 and over.

\section{Consent for publication}

Not applicable.

\section{Competing interests}

The authors declare that they have no competing interests.

\section{Author details}

${ }^{1}$ Department of Preventive and Public Health Dentistry, Faculty of Dentistry, Universitas Indonesia, Jalan Salemba No. 4, Jakarta 10430, Indonesia. ${ }^{2}$ Department of Pediatric Dentistry and Dental Public Health, Faculty of Dentistry, Alexandria University, Alexandria, Egypt. 
Received: 8 August 2020 Accepted: 29 December 2020

Published online: 07 January 2021

\section{References}

1. Moorhead SA, Hazlett DE, Harrison L, Carroll JK, Irwin A, Hoving C. A New dimension of health care: systematic review of the uses, benefits, and limitations of social media for health communication. J Med Internet Res. 2013;15(4):e85.

2. Maharani DA, Zhang S, Gao SS, Chu C-H, Rahardjo A. Dental caries and the erosive tooth wear status of 12-year-old children in Jakarta, Indonesia. Int J Environ Res Public Health. 2019;16(16):2994.

3. Council on Clinical Affairs, Committee on the Adolescent. Adolescent oral health care. American Academy of Pediatric Dentistry; 2015;40(6).

4. Maharani DA, Adiatman M, Rahardjo A, Burnside G, Pine C. An assessment of the impacts of child oral health in Indonesia and associations with self-esteem, school performance and perceived employability. BMC Oral Health. 2017;17(1):65

5. Maida CA, Marcus M, Hays RD, et al. Child and adolescent perceptions of oral health over the life course. Qual Life Res. 2015;24(11):2739-51.

6. Grootens-Wiegers $\mathrm{P}$, Hein IM, van den Broek JM, de Vries MC. Medical decision-making in children and adolescents: Developmental and neuroscientific aspects. BMC Pediatr. 2017:17(1):120.

7. Silk H, Kwok A. Addressing adolescent oral health: a review. Pediatr Rev. 2017:38(2):61-8

8. O'Keeffe GS, Clarke-Pearson K, et al. The Impact of social media on children, adolescents, and families. Pediatrics. 2011;127(4):800-4.

9. Fergie G, Hunt K, Hilton S. Social media as a space for support: Young adults' perspectives on producing and consuming user-generated content about diabetes and mental health. Soc Sci Med. 2016;170:46-54.

10. Melkers J, Hicks D, Rosenblum S, Isset KR, Elliott J. Dental blogs, podcasts, and associated social media: descriptive mapping and analysis. J Med Internet Res. 2017;19(7):e269.

11. El Tantawi M, Bakhurji E, Al-Ansari A, et al. Indicators of adolescents' preference to receive oral health information using social media. Acta Odontol Scand. 2019;77(3):213-8.

12. Solahudin D, Fakhruroji M. Internet and Islamic learning practices in Indonesia: Social media, religious populism, and religious authority. Religions. 2020;11:19.

13. Jamnadass E, Aboumarzouk $\mathrm{O}$, Kallidonis $\mathrm{P}$, Emiliani E, Tailly T, Hruby S, Sanquedolce F, Atis G, Ozsoy M, Greco F, Somani BK. The role of social media and internet search engines in information provision and dissemination to patients with kidney stone disease: A systematic review from European Association of Urologists Young Academic Urologists. J Endourol. 2018:32(8):673-84.

14. Mager A. Search engines matter: From educating users towards engaging with online health information practices. Policy \& Internet. 2012:4(2):1-21.

15. Wang L, Wang J, Wang M, Li Y, Liang Y, Xu D. Using Internet search engines to obtain medical information: a comparative study. J Med Internet Res. 2012;14(3):e74.

16. Fan KL, Graziano F, Economides JM, Black CK, Song DH. The public's preferences on plastic surgery social media engagement and professionalism: Demystifying the impact of demographics. Plast Reconstr Surg. 2019:143(2):619-30

17. Shetty V, Yamamoto J, Kenneth YK. Re-architecting oral healthcare for the 21st century. J Dent. 2018;74:S10-4

18. Masters K. Edgar Dale's pyramid of learning in medical education: a literature review. Med Teach. 2013:35(11):e1584-1593.

19. https://www.thejakartapost.com/news/2012/08/01/jakarta-named-world -s-most-active-twitter-city.html

20. https://www.statista.com/statistics/284437/indonesia-social-networkpenetration/

21. Bounsanga J, Voss MW, Crum AB, Hung M. The association between perceived health status and health information communication channels. J Health Commun. 2016;21(11):1148-52.

22. Lee PJ. Should we adjust for a confounder if empirical and theoretical criteria yield contradictory results? A simulation study. Sci Rep. 2014;4:6085.

23. Hassona Y, Qutachi T, Dardas L, Alrashdan MS, Sawair F. The online attention to oral cancer research: an Altmetric analysis. Oral Dis. 2019;25(6):1502-10

24. Bandura A. Social learning theory. Englewood Cliffs: Prentice-Hall; 1977.

25. Gunther AC, Storey JD. The influence of presumed influence. J Commun. 2003:53(2):199-215

26. Ajzen I. The theory of planned behavior. Organ Behav Hum Decis Process. 1991:50:179-211.

27. Tse CK, Bridges SM, Srinivasan DP, Cheng BS. Social media in adolescent health literacy education: a pilot study. JMIR Res Protoc. 2015;4(1):e18.

28. Forgeron PA, McKenzie E, O'Reilly J, Rudnicki E, Caes L. Support for my video is support for me: a youtube scoping review of videos including adolescents with chronic pain. Clin J Pain. 2019;35(5):443-50.

\section{Publisher's Note}

Springer Nature remains neutral with regard to jurisdictional claims in published maps and institutional affiliations.
Ready to submit your research? Choose BMC and benefit from:

- fast, convenient online submission

- thorough peer review by experienced researchers in your field

- rapid publication on acceptance

- support for research data, including large and complex data types

- gold Open Access which fosters wider collaboration and increased citations

- maximum visibility for your research: over 100M website views per year

At $B M C$, research is always in progress.

Learn more biomedcentral.com/submissions 